\title{
Study on Aesthetic Characteristics of Musical Performance
}

\author{
Jing Liang \\ Weinan Normal University, Weinan, Shaanxi, 714000
}

Keywords: music performance; aesthetic characteristics; actress

\begin{abstract}
This paper studies and discusses the performance of music aesthetic process at the height of aesthetics. It is based on the author's many years of playing experience plus the theoretical study during the postgraduate study, from the music research, data search, technical practice, performance psychological exercise, to the understanding of the connotation of specific music works, the player's own unique interpretation of the work into the specific performance activities, and finally the performance of the meaning of the work.
\end{abstract}

\section{Introduction}

Music, due to the particularity of its material materials, causes people to create, play, appreciate, understand, interpret and other aspects of music art different from other art categories, and the "playing" is the realization of specific music works. basis. Without performance, music is just a concept that is not circulated by everyone; without performance, the meaning of music cannot be realized, so that it can be realized by the aesthetic subject; without music, the complete musical aesthetic will lose its original sensory enjoyment. Therefore, performance can be seen as the basis for supporting the development of music. In the long history of music, it would be unthinkable to have no research and study on music performance. Music is the art of time, so the movement of music can only reflect its temporal nature in performance. At the same time, the aesthetic characteristics of music in the time, as the interpreter's performer, must grasp the extremely comprehensive and express it, in order to realize the complete aesthetic process of the audience from sensory pleasure to thought. It can be seen that the performance of music is not an independent part of the music. It is based on the creation of the composer, with the aim of the audience's aesthetics, and the player's own understanding of the work links them.

\section{Music Performances for the Second Creation of Music}

Heidegger's existence and existence of music is to interpret the difference between subject and object from the perspective of philosophy. Why is it because of the dialectical relationship between the performance of music and the second creation of music. Heidegger distinguishes between phenomena and nature from being and being. The person is sensory, proving that something is already present or generated. The form of works such as the existence of music. And existence means the means or means of expression that enables the person to become a person. In this sense, the existential meaning and form of the "ontology" in different "existing bodies" are different. This is also Gadamer's understanding. That is to understand, it is not the only possibility of the way the subject is constructed, but it is the form of its own existence. In a musical performance, the performer's understanding of the work can be the music itself, or it can be other. Hegel explained this question in "Logic" and attributed this to the possibility that the presentation of phenomena is the essence of development. The essence is the factor that causes the cause, and the cause is the initial cause of the result of the essence. Both sides depend on each other and infiltrate each other. The performance of music is the process of the restoration of the essence of phenomena creation and phenomena. This is one of Husserl's theory of phenomenology. Husserl believes that different phenomena are traced to the same essential cause, that is, identity. This is also the main basis for the criticism of phenomena. Husserl's student Ingarden explained in depth the difference between the existence and the essence of music. In the end, it is concluded that "the musical works are not the 
object of the material", nor can they be called the object of concept, but the object of pure intentionality. Regarding music performances and second-degree creations, Ingarden believes that faithful reproduction or reconstruction of the composer's performance, according to the composer's intention to carry out creative performances, can be called the original creation of his musical works. This statement by Ingarden affirmed the "existence" of the second creation. The "existence" of the second creation was also judged by the listener's intention.

\section{The Perfect Music Performance is the Realization of the Value and Meaning of Music Works.}

As an important part of the music creation process, music performance plays an important role in the formation of music value. A work is valuable, of course, referring to the composer's creation and writing on the score. Only through musical performances, performing arts can make original works and works that are worthwhile. How to get the value of the work and make it into an effective value is the subject that all performers face. For the performer, the creativity is far less than the creation of a composer.

The performer interprets the musical works and leaves the performances of the performers. The interpretation of the musical works is impossible. The music performers interpret the most basic things in the musical works, and the second is to have creative interpretation works. The former is what the performer must do, and it is the basis for interpreting music. The latter is a mature feature of an excellent music performance artist. In the performing arts, the musical interpretation with creative and distinctive characteristics will give people a refreshing feeling. Creative music interpretation is also the most popular among experts. The perfect performance re-creation enhances the aesthetic value of the work. In turn, an excellent musical work, in the low-energy performers, without the interpretation of the works, will eclipse the works, making the works unrecognizable, and the performers will perform the works on the music. Interpretation, the materialized "text" becomes a real and sensible sound, and the works recorded by the composer on the music score are only the possibility of sound, and the music performance makes the possibility of sound become a reality. If the composer's work is not performed by the performer, its value is only potential. Just as the painter's painting does not go through the exhibition, the literary works are not in the warehouse and can't meet the readers, and can't exert its aesthetic function. Thanks to the performance and singing of the performers, the musical "text" that makes the music materialized becomes a "living", sporty, emotional and full of meaning, and the performance is the composition of the composer's materialized form and the performer's interpretation of the work. The combination has become a "living art", which enables the aesthetics to communicate well with the musical works, and also reflects the value of the musical works, so that the aesthetics can enjoy the musical aesthetic pleasure.

Some works that have their own objective characteristics, some people like it, think that it contains the characteristics of beauty, and have aesthetic value; while others have the opposite conclusion. The standards of human hobbies and music are different in different historical periods. As living conditions change, human needs and human consciousness are changing. At the same time, the content and expressions expressed in the creation are also changing. The value of a musical piece lies in its ability to evoke resonance among the appreciators, which gives the viewers a happy, cheerful emotion that is different from any other emotion associated with use value or moral value. . Modern value science completely separates aesthetic values from moral values and use values, and believes that they are established on different values.

\section{Characteristics of Music Performance Art Aesthetics}

The performance of vocal music, the appreciator has already had some aesthetic preparation before enjoying it. Appreciators have their own understanding of the performing arts of vocal music through their own past art appreciation, and have produced aesthetic expectations and psychology, which can form an aesthetic preparation for this vocal performance art in their own psychology. 
Appreciators are able to carry out the main motivations of aesthetic activities. In the life experience of people, different things will leave different impressions, thus helping people to form an understanding of things. The same is true for art appreciation. Appreciators form an aesthetic understanding of vocal music through the past vocal performance art. Before each artistic performance of vocal music in the future, they will form an aesthetic expectation based on the inherent aesthetic understanding and ability. Aesthetic preparations are formed before the aesthetic activities begin. This kind of aesthetic preparation will encourage the audience to produce aesthetic desires and encourage the audience to carry out aesthetic activities. On the other hand, this aesthetic preparation will also produce a preconceived notion. If in the past vocal performances, the audience's aesthetic expectations are not met. Then, in the art of vocal performances in the future, the audience will have some misunderstandings based on their past aesthetic expectations of aesthetic activities. Such aesthetic preparation is not conducive to the progress of vocal performance art, and the charm of vocal music cannot be Yokota play.

After the beginning of the vocal performance, the appreciator will have a comprehensive psychological experience in this process, and this psychological feeling is the aesthetic feeling. Aesthetic feelings are more complicated, but it is an important part of art appreciation. In the vocal performance art event, the charm of the vocal music works is presented to the viewer by the performer's performance. In the process, all kinds of information will make the audience react, for example, in the performance of the performer. At the same time, through the interaction with the audience to increase the audience's appreciation enthusiasm, so that the player can interact with the audience in the process of this activity to promote the smooth completion of the event, but also enhance the aesthetic acceptance of the new appreciator. In the performing arts of vocal music, the performers can effectively promote the beautiful display of the vocal performance through various kinds of information, and generate emotional communication with the audience, awaken the audience's recognition of the vocal performance art, and resonate with the audience. Promote the development of the audience's aesthetic feelings. This aesthetic feeling can bring a pleasant feeling to the audience and satisfy the audience's aesthetic expectation for the vocal performance art activities. On the other hand, the audience shows satisfaction with the art of vocal performance, such as giving troubles and cheers in the wonderful part, which can in turn promote the vocal player to gain greater motivation and better play their own performance. Level, the performance of the music is more perfect. Therefore, the aesthetic feeling of the audience is an important spiritual communication activity.

After the end of the aesthetic activities, the audience's expectation of life and death is satisfied, and the aesthetic feelings are also obtained in the event. Then, after the aesthetic activities are over, there will be aesthetic reservations. Because after the end of this kind of appreciation activity, the good and beautiful experience that the audience has won will not disappear immediately, and it will stay on the audience. This aesthetic reserve exists in the hearts of the audience. After continuous accumulation, it will have a certain impact on the audience's future aesthetic activities, so that the audience's psychology will be purified. In the appreciation of literary works, the remaining is the highest realm of literary appreciation, and at the same time, it is also the highest realm of artistic appreciation. If the vocal performance art can have a vivid performance scene, then the reserved space for the audience will be greater, thus purifying the audience's mind more.

\section{Conclusion}

The development of vocal music in China is also a long time. In the process of development and change, it has become a part of Chinese traditional culture. Until now, vocal music has been a way of entertainment for us. Vocal music is performed mainly through the combination of the player's limbs and instruments and the combination of body and vocal music. In the performance of vocal music, its artistic aesthetic features play an important role. 


\section{Acknowledgements}

Fund Project:

1) 2017 National Art Fund Project (2017-A-04- (050) -0564)

2) Shaanxi Province in 2017 military and civilian integration research fund project (17JMR06)

3) Weinan Teachers College of Education Science International Cooperation Project (17GJHZ10)

\section{References}

[1] Fu Li. Exploring the Aesthetic Features of Vocal Music Performing Arts from the Perspective of Aesthetic Theory [J]. Drama House, 2015(18):80.

[2] Li Jingwei. Accepting the Artistic and Aesthetic Value of Researching Vocal Music in the Perspective of Aesthetics [J]. Drama House, 2015(20): 87.

[3] Tang Science. Accepting Aesthetics to Explore the Aesthetic Characteristics of Vocal Performance Art [J]. Northern Music, 2015(11): 59-60

[4] Wu Biling. The Aesthetic Features of Contemporary Chinese National Vocal Music Art[J]. Journal of Dali University, 2008, (09). 